\title{
14. PHYSICAL PROPERTIES OF SAMPLES FROM THE JOIDES, LEG 37, DEEP SEA DRILLING PROJECT
}

\author{
H.H. Schloessin and Z.D. Dvorak, Department of Geophysics, \\ University of Western Ontario, London, Canada
}

\section{INTRODUCTION}

The following are some preliminary results of experiments conducted to determine the nature of physical property variations in rocks of the MidAtlantic Ridge. The broad nature of these variations is thought to be attributable to four main variables: pressure, temperature, change in state of oxidation, and change in state of hydration. The laboratory studies comprise two kinds of experiments: (a) high-pressure experiments, using a 1000-ton capacity cubic press, meant to determine and compare the effects of quasihydrostatic pressure and temperature, and (b) high-vacuum experiments meant to determine and compare the effects of temperature and of $\mathrm{H}_{2} \mathrm{O}$ adsorption or desorption. Thermal and electrical conductivity coefficients have been chosen as suitable and diagnostically significant parameters. Because of the extremely long equilibrium times involved, only a few series of experiments have been completed so far and investigations are still in progress.

\section{SAMPLE PREPARATION}

For the high vacuum part of the experiment, samples were prepared as discs $0.33 \mathrm{~cm}$ thick obtained by slicing the 1 -in. minicores. All samples were thoroughly rinsed and cleaned in water, then washed and dried in acetone. For the high-pressure part of the experiments smaller, 0.64-cm diameter, discs were cored out of the samples used in the high-vacuum experiments.

A preselection of the most suitable sample discs was made by optical inspection. Direct beam X-ray absorption topographs of the preselected samples were taken to determine grain distribution, homogeneity, and possible flaws. From the photographic images (Plates 1-4) the most homogeneous sample was chosen for the experiments.

Each series of experiments was preceded by measurements of the electrical conductivity of the sample in the laboratory atmosphere. Initial and final values attained after $1 / 2$ to $1 \mathrm{hr}$, were noted as well as differences between readings taken with and without guard ring and changes in response to variations of the test voltage $(10-1000 \mathrm{v})$.

\section{LATTICE THERMAL CONDUCTIVITY $(\lambda)$; VARIATIONS WITH PRESSURE (P) AND TEMPERATURE (T)}

Measurements were performed in the steady state on two $(0.64-\mathrm{cm}$ diameter) discs of different thicknesses mounted in $(3.8 \mathrm{~cm})$ pyrophyllite cubes. The hot wire $(\mathrm{Pt})$ method was used, which involves the measurements of current $(j)$, voltage $(v)$ and of both the absolute and differential emf's of two $(\mathrm{Pt} / \mathrm{Pt} 10 \% \mathrm{Rh})$ thermocouples, placed at the surfaces of the two discs. The thermal conductivity coefficients $(\lambda)$ were calculated from the cylindrical heat-flow equation (Carslaw and Jaeger, 1959)

$$
\lambda=\frac{q \times j \times \mathrm{v} \ln \left(r_{2} / r_{1}\right)}{2 \pi L\left(\mathrm{~T}_{1}-\mathrm{T}_{2}\right)}
$$

where $L$ denotes the length of the heater wire and $q=$ 0.24 . Accounting for $\pm 0.3 \mathrm{~K}$ error in temperature determination, $\pm 0.02 \mathrm{~cm}$ in the position of the thermocouple probes and an error of less than $1 \%$ in the determination of $j \times \mathrm{v}$ the values of $\lambda$ are estimated to be affected by a maximum percentage error of $\pm 14 \%$.

In high-pressure experiments on single crystals this steady-state method was found to give the most reliable results. Detail of probable errors and a discussion on limitations of the method have been given for applications to measurements of the lattice conductivity of enstatite (Schloessin and Dvorak, 1973) and $\alpha$ quartz (Darbha and Schloessin, 1975).

Variations of $\lambda$ for Samples 332A-16-1, 33-36 cm (3) and $332 \mathrm{~B}-37-3,54-56 \mathrm{~cm}$ with pressure and inverse temperature are shown in Figures 1 and 2. The partial variations of $\lambda$ with $P$ and $T$ are:

\begin{tabular}{lcc}
\hline & $\begin{array}{c}(\Delta \lambda / \Delta \mathrm{P}) \mathrm{T} \\
\left(\mathrm{mcal} \mathrm{deg}-1 \mathrm{~cm}^{-1} \mathrm{sec}^{-1} \mathrm{~Kb}^{-1}\right)\end{array}$ & $\begin{array}{c}(\Delta \lambda / \Delta \mathrm{T}) \mathrm{P} \\
\left(\mathrm{mcal} \mathrm{deg}^{-2} \mathrm{~cm}^{-1} \mathrm{sec}^{-1}\right)\end{array}$ \\
\hline $332 \mathrm{~A}-16-1$ & $4.0 \times 10^{-2}$ at $352 \mathrm{~K}$ & $-1.9 \times 10^{-2}$ at $25 \mathrm{Kbar}$ \\
& $1.6 \times 10^{-2}$ at $443 \mathrm{~K}$ & $-2.6 \times 10^{-2}$ at $56 \mathrm{Kbar}$ \\
$332 \mathrm{~B}-37-3$ & $8.1 \times 10^{-2}$ at $301 \mathrm{~K}$ & $-3.3 \times 10^{-2}$ at $19 \mathrm{Kbar}$ \\
& $3.1 \times 10^{-2}$ at $426 \mathrm{~K}$ & $-4.9 \times 10^{-2}$ at $56 \mathrm{Kbar}$ \\
Values of $\lambda$, extrapolated to zero pressure, are \\
332A-16-1 & $4.74 \mathrm{mcal} \mathrm{deg}^{-1} \mathrm{~cm}^{-1} \mathrm{sec}^{-1}$ at $318 \mathrm{~K}$ \\
& $3.13 \mathrm{mcal} \mathrm{deg}-1 \mathrm{~cm}^{-1} \mathrm{sec}^{-1}$ at $443 \mathrm{~K}$ \\
$332 \mathrm{~B}-37-3$ & $5.25 \mathrm{mcal} \mathrm{deg}-1 \mathrm{~cm}^{-1} \mathrm{sec}^{-1}$ at $301 \mathrm{~K}$ \\
& $2.25 \mathrm{mcal} \mathrm{deg}-1 \mathrm{~cm}^{-1} \mathrm{sec}^{-1}$ at $426 \mathrm{~K}$ \\
\hline
\end{tabular}

Results, obtained so far, do not confirm the positive temperature coefficient for the lattice thermal conductivity of basalt found in earlier investigations by Poole (1914) and Bridgman (1931). However, a comparison with the thermal conductivity measurements on a greater number of basalts of different origins per- 


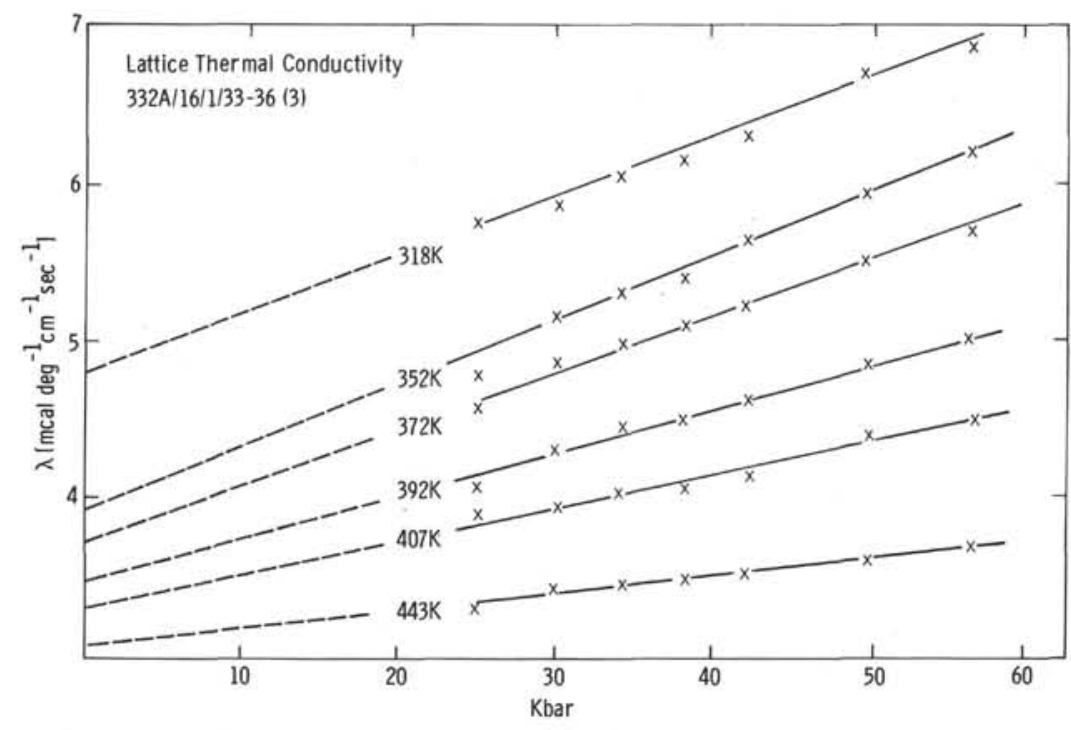

Figure 1a. Variations of lattice thermal conductivity $(\lambda)$ with pressure and temperature for (a) 332A-16-1, and (b) 332B-37-3.

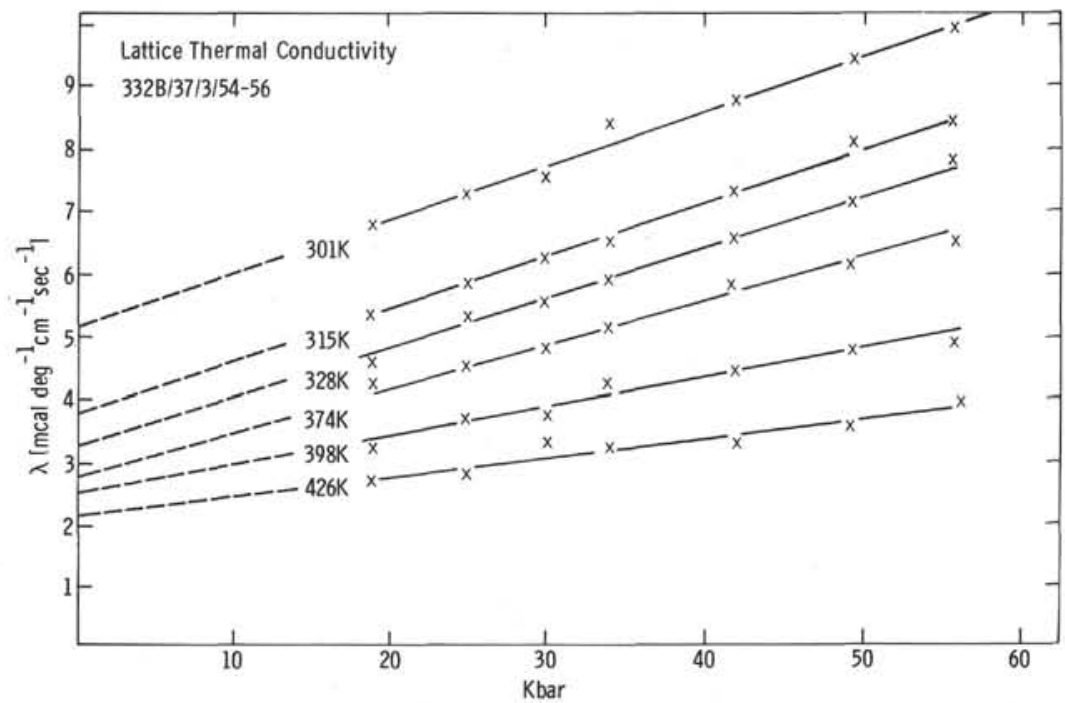

Figure $1 \mathrm{~b}$. Variations of lattice thermal conductivity $(\lambda)$ with pressure and temperature for (a) 332A-16-1, and (b) 332B-37-3.

formed by Petrunin et al. (1971) would seem to suggest that the positive temperature coefficient is exceptional and possibly characteristic of glassy basalt only.

The temperature coefficient increases noticeably with increasing pressure. Pore closure as a result of highpressure exposure and variations in specific mineral content are probably accountable for the difference between values extrapolated to zero pressure and those inferred from heat-flow measurements made on Hole 332A (Hyndman, DSDP Leg 37, Shipboard Hole Summary). The extrapolated values for the lower temperatures, however, agree reasonably well with the average thermal conductivity of $4.9 \mathrm{mcal} \mathrm{deg} \mathrm{dem}^{-1} \mathrm{sec}^{-1}$ of metabasalt given by Hyndman and Jessop (1972) and the mean values of 4.01 and $3.98 \mathrm{mcal} \mathrm{deg}^{-1} \mathrm{~cm}^{-1} \mathrm{sec}^{-1}$ for the Hole 332A and 332B samples as determined by Hyndman and Drury (this volume) at $21{ }^{\circ} \mathrm{C}$.

\section{ELECTRICAL CONDUCTIVITY $(\sigma)$; VARIATIONS WITH PRESSURE (P) AND TEMPERATURE (T)}

D.C. electrical conductivity coefficients were calculated from resistance measurements made by means of a Hewlett-Packard model 439A highresistance meter and Keithley model 616 digital electrometer. High-pressure experiments were carried out on samples previously used in high-vacuum experiments. Accounting for errors in temperature of the order of $\pm 0.3 K$ for $\mathrm{T}<1000 \mathrm{~K}$ and errors increasing to $\pm 20 \mathrm{~K}$ on approach to the melting point near $1800 \mathrm{~K}$, errors less than $\pm 2 \%$ in the determination of pressure, and a probable error of $\pm 4 \%$ in resistance measurements, the maximum percentage error for $\sigma(\mathrm{P}, \mathrm{T})$ was estimated to be of the order of $\pm 10 \%$. 


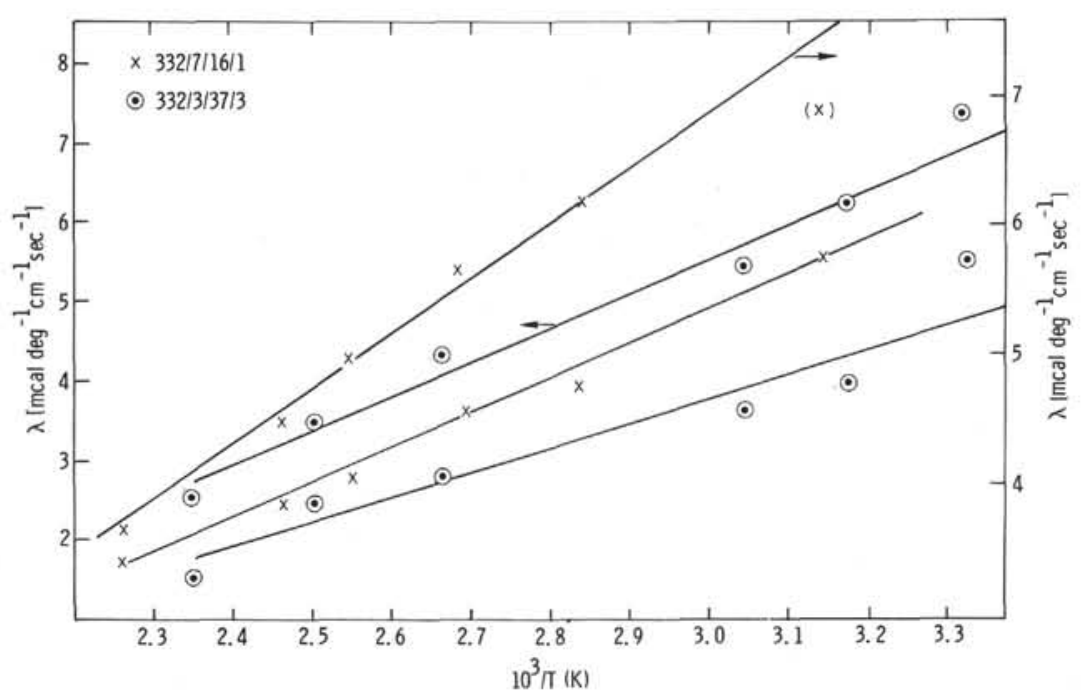

Figure 2. Variations of $\lambda$ with $1 / T$.

Results for 332A-16-1, 33-36 cm (3), 332B-21-1, 99 $102 \mathrm{~cm}$, and 332B-37-3, 54-56 cm, as shown in Figure 3, may be summarized as follows:

\begin{tabular}{lcc}
\hline & $\begin{array}{c}1 / \sigma(\Delta \sigma / \Delta \mathrm{P})_{\mathrm{T}} \\
\left(\mathrm{Kbar}^{-1}\right)\end{array}$ & $\begin{array}{c}1 / \sigma(\Delta \sigma / \Delta \mathrm{T}) \mathrm{P} \\
\left(\mathrm{K}^{-1}\right)\end{array}$ \\
\hline $332 \mathrm{~A}-16-1$ & $4.1 \times 10^{-3}$ at $491 \mathrm{~K}$ & $8.2 \times 10^{-2}$ at $19 \mathrm{Kbar}$ \\
& $2.9 \times 10^{-3}$ at $351 \mathrm{~K}$ & $2.5 \times 10^{-3}$ at $56 \mathrm{Kbar}$ \\
$332 \mathrm{~B}-21-1$ (4.8) & $4.8 \times 10^{-2}$ at $566 \mathrm{~K}$ & $1.65 \times 10^{-1}$ at $19 \mathrm{Kbar}$ \\
& $9.4 \times 10^{-2}$ at $321 \mathrm{~K}$ & $3.25 \times 10^{-1}$ at $56 \mathrm{Kbar}$ \\
$332 \mathrm{~B}-37-3$ & $9.2 \times 10^{-2}$ at $570 \mathrm{~K}$ & $8.9 \times 10^{-2}$ at $19 \mathrm{Kbar}$ \\
& $1.2 \times 10^{-2}$ at $377 \mathrm{~K}$ & $3.0 \times 10^{-1}$ at $56 \mathrm{Kbar}$ \\
\hline
\end{tabular}

Activation energies ( $\epsilon$, their pressure and temperature derivates, as well as preexponential constants $\left(\sigma_{o}\right)$ have been determined under the assumption that the conductivity is sufficiently well represented by one or several terms of the form $\sigma=\sigma_{0} \exp (-\epsilon / k \mathrm{~T})$.

\begin{tabular}{ccccc}
\hline & $\begin{array}{c}\epsilon \\
{[\text { e.v. }]}\end{array}$ & $\left.\begin{array}{c}(\Delta \epsilon / \Delta \mathrm{P}) \\
{[\text { e.v. Kbar }}\end{array}{ }^{-1}\right]$ & $\begin{array}{c}(\Delta \epsilon / \Delta \mathrm{T}) \\
{\left[\text { e.v. } \mathrm{K}^{-1}\right]}\end{array}$ & $\begin{array}{c}\sigma_{\mathrm{O}} \\
{\left[\Omega^{-1} \mathrm{~cm}^{-1}\right]}\end{array}$ \\
\hline 332A-16-1 & $0.34-0.51$ & $3.8 \times 10^{-4}$ & $7.1 \times 10^{-6}$ & $8.2 \times 10^{-2}$ \\
& $0.35-0.86$ & $8.0 \times 10^{-5}$ & $6.5 \times 10^{-6}$ & \\
332B-21-1 & $0.35-0.63$ & $2.6 \times 10^{-4}$ & $1.4 \times 10^{-5}$ & $8.0 \times 10^{-5}$ \\
& $0.44-0.90$ & $2.34 \times 10^{-4}$ & $8.2 \times 10^{-6}$ & $8.2 \times 10^{-2}$ \\
332B-37-3 & $0.44-0.67$ & $3.1 \times 10^{-4}$ & $9.8 \times 10^{-6}$ & $4.3 \times 10^{-5}$ \\
& $0.35-0.99$ & $3.7 \times 10^{-4}$ & $8.6 \times 10^{-6}$ & $1.5 \times 10^{-1}$ \\
\hline
\end{tabular}

These results seem to support the contention, based mainly on the optical and electrical properties of its mineral constituents, that the electrical conductivity of basalt is predominantly of extrinsic electronic nature. There are some indications of contributions from possibly ionic migration mechanisms to be found in relatively large $\Delta \epsilon / \Delta p$ variations near room temperature and close to the melting point. Activation energies and $\sigma_{o}$ values are in general agreement with those known for different types of rocks (Coster, 1948) and specific minerals (Hughes, 1955; Bradley et al.

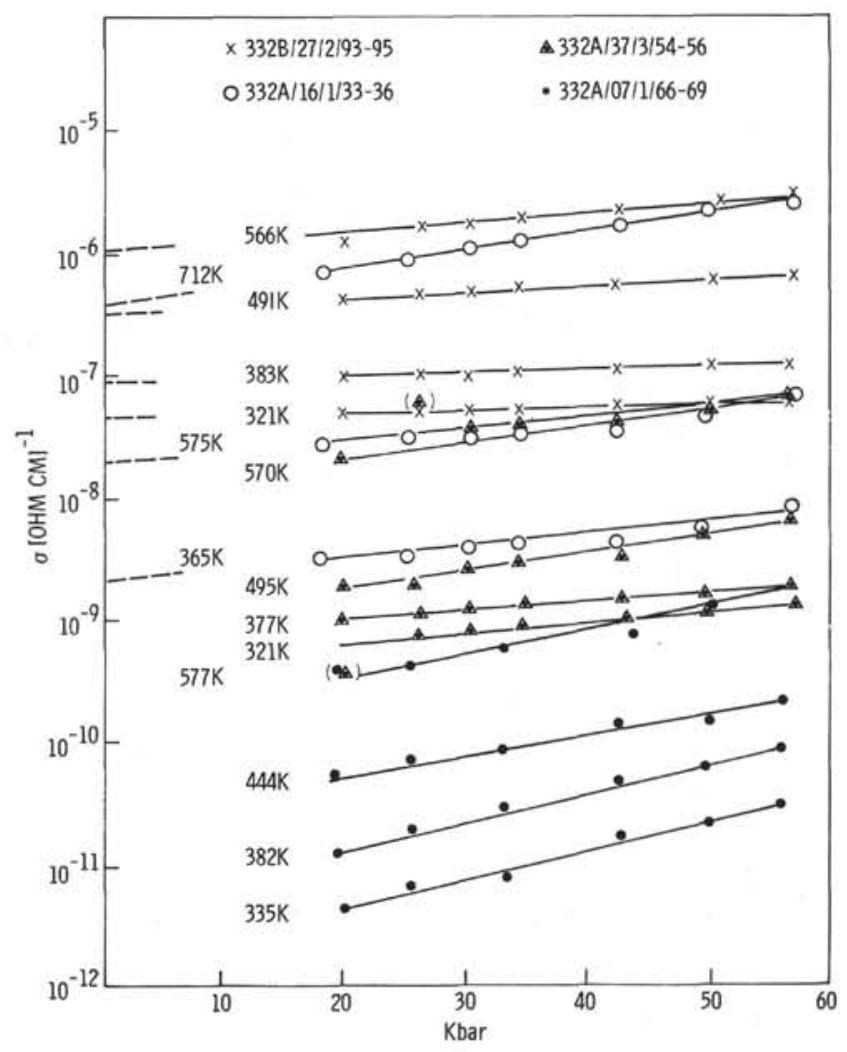

Figure 3. Variations of $(d c)$ electrical conductivity $(\sigma)$ with pressure and temperature.

1964; Dvorak and Schloessin, 1973). It should be noted that the activation energies are on the whole considerably lower than the energy of 0.77 e.v. for ion exchange in water (Gonvec, 1962; Bradley et al., 1970).

The derivatives of $1 n \epsilon$ with respect to pressure and temperature are to a first approximation determined by $1 / k \mathrm{~T} \delta \epsilon / \delta \mathrm{p}$ and $1 / k \mathrm{~T} \delta \epsilon / \delta \mathrm{T}$. In view of this, estimates of the ratio of compressibility $(\beta)$ to thermal expansion coefficient $(\alpha)$ may be obtained from the relationship (Jost and Mennenöh, 1950). 


$$
\delta \epsilon / \delta \mathrm{p} \cong-\beta / \alpha \delta \epsilon / \delta \mathrm{T}
$$

which holds only inasfar as changes of $\sigma$ with $\mathrm{P}$ and $\mathrm{T}$ are functions of changes in volume or lattice parameter with $\mathrm{P}$ and $\mathrm{T}$.

Combining, for example, values of the pressure derivatives of $\sigma$ at the higher temperatures with the temperature derivatives at the lowest pressure, gives values for $\beta / \alpha$ between $1.7 \times 10^{-8}$ and $4.2 \times 10^{-9} \mathrm{deg}$ dyn $^{-1} \mathrm{~cm}^{2}$ and still lower values at the higher pressures. They are one to two orders of magnitude smaller than ratios calculated from values of $\beta$ and $\alpha$ at ordinary pressures and temperatures (e.g., corundum $7.5 \times 10^{-8}$, calcite $1.7 \times 10^{-7}$, and quartz $2.2 \times 10^{-7} \mathrm{deg}$ dyn $^{-1}$ $\mathrm{cm}^{2}$ ). This result can only partly be accounted for by the internal stresses acquired during the high-pressure treatment as a result of internal inhomogeneities, and should, therefore, reflect on the values for $\beta / \alpha$ that should be used in theoretical estimates of the elastic strain energy due to internal stresses. They are important to considerations (Walsh, 1973) of strain energy content in rocks which are subjected to displacements within the earth's pressure and temperature field.

\section{INDICATIONS, FROM CONDUCTIVITY MEASUREMENTS, OF MELTING AND SOLIDIFICATION}

Conductivity variations up to and beyond the melting point of Samples 332A-16-1, 33-36 cm (3) and 332B-37-3, 64-56 cm are shown in Figures 4 and 5. Values for the activation energy lie between 0.8 and 2.1 e.v., but mostly around 1.1-1.4 e.v. suggesting that the dominant conduction mechanism remains extrinsic up to the melting point. The activation energies at the higher temperatures are just slightly higher than those found in most of the earlier electrical conductivity studies of basalts which have been summarized by Presnall et al. (1972). This, however, is not surprising considering that the present measurements have been performed at considerably higher pressures.

On the basis of Scheidegger's (1973) estimates of depths and temperature for magma generation, melting of Mid-Atlantic Ridge samples would be expected to occur at about $1330^{\circ} \mathrm{C}$ and $8 \mathrm{Kbar}$. Applying an increase in solidus temperature with pressure the value of $12 \mathrm{~K} \mathrm{Kbar}^{-1}$ determined by Kushiro et al. (1968) for anhydrous lherzolite, one would expect the melting temperature corresponding to 40 and $50 \mathrm{Kbar}$ to increase to $1710^{\circ}$ and $1830^{\circ} \mathrm{C}$, respectively. Since this coincides more or less exactly with the range over which melting at 40 and $50 \mathrm{Kbar}$ has been observed, Scheidegger's choise of combining $\mathrm{P}$ and $\mathrm{T}$ may be regarded as close to adequate characterization of the actual situation at the depth of magma generation.

Conductivity variations with $1 / \mathrm{T}$ up to the melting point and detail of variations through melting on heating and solidification on cooling at 40 and $50 \mathrm{Kbar}$ are shown in Figures 4 and 5. The conductivity curves through melting of basalt as obtained by Presnall et al. (1972) are shown for comparison. Apart from a shift towards higher conductivities, probably mostly as a result of high pressure, the general behavior of the

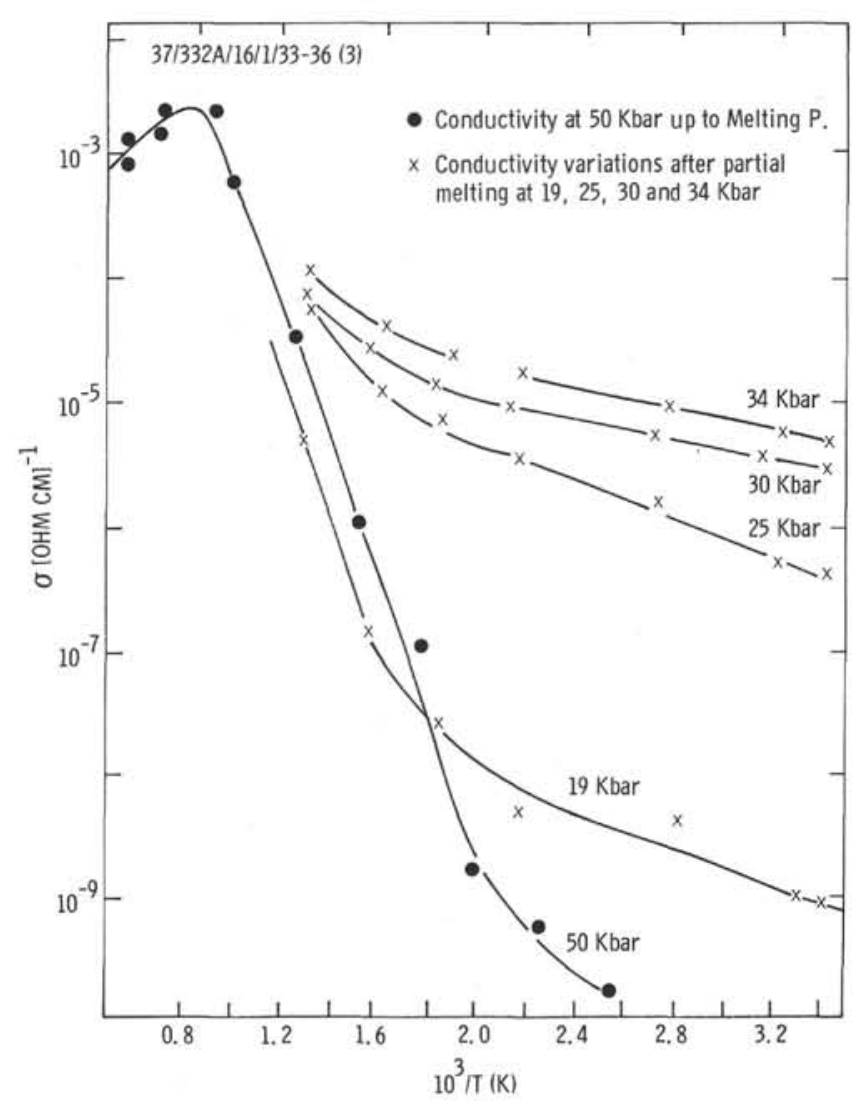

Figure 4. Variations of $\sigma$ with $1 / T$ for 332A-16-1, up to the melting point at $50 \mathrm{Kbar}$ and after partial melting at $19,25,30$, and $34 \mathrm{Kbar}$.

variations below $1200 \mathrm{~K}$ for both melting and cooling is similar to the one previously found at atmospheric pressure. However, in contrast with most previous observations, the present measurements of variations through the melting point show (a) certain premonitory effects, occuring over a wide temperature range prior to melting and solidification, and (b) a pronounced, transient, decrease in conductivity just before melting or solidification takes place. At temperatures above the melting point the conductivity of the homogeneous melt is found to be considerably higher than the solid conductivity in agreement with previous results. There are several reasons why one would expect the conductivity variations observed in the current and previous experiments to show significant differences. Firstly, the present conductivity values are d.c. conductivities, whereas most previously reported results (Presnall et al., 1972; Khitarov et al., 1970) are concerned with a.c. conductivities. Secondly, present measurements were made on bulk, polycrystalline, samples, whereas most previous experiments were performed on powders (Khitarov et al., 1970; Lebedev and Khitarov, 1964), and some on homogeneous glasses, prepared by quenching of premolten samples of basaltlike chemical composition (Presnall et al., 1972). In the case of powders necking between adjacent particles during incipient melting the observed conductivity is bound to increase. Thirdly, previous measurements at 


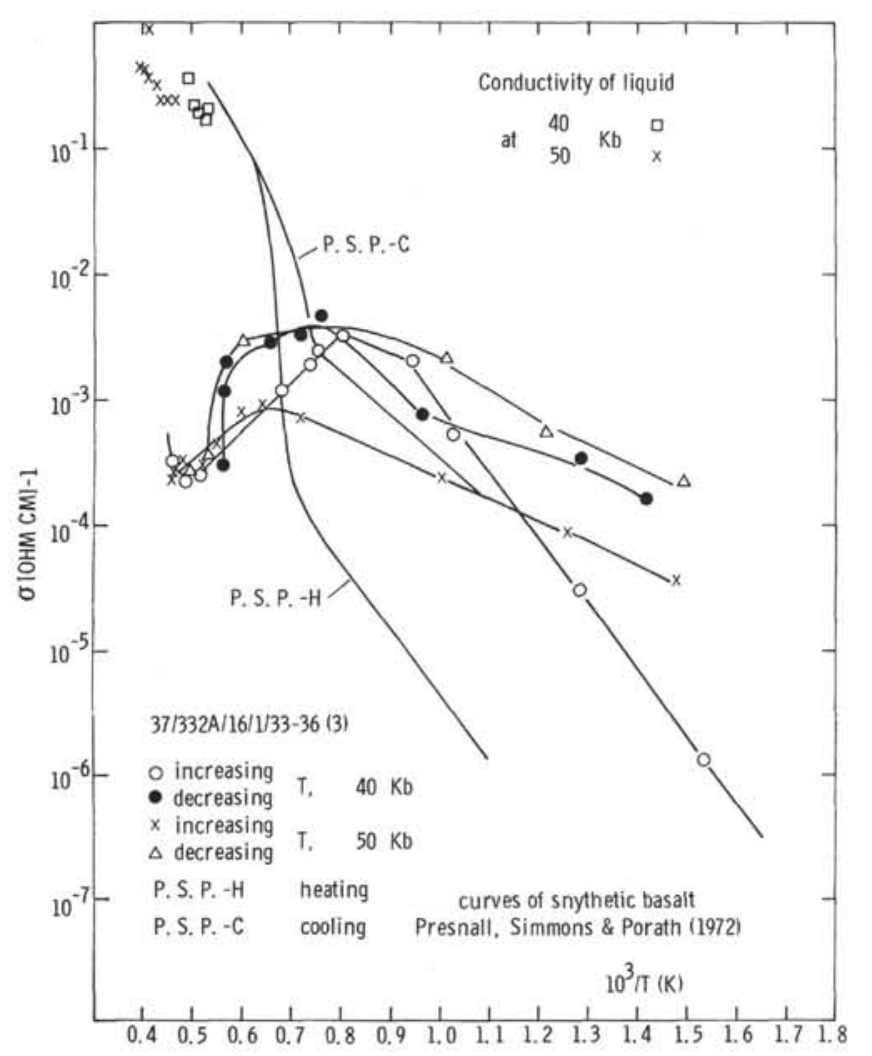

Figure 5. Variations of $\sigma$ versus $1 / T$ during melting and solidification. Conductivity curves for heating and cooling of synthetic basalt, marked P.S.P. - H and P.S.P. - C, as determined by Presnell, et al, (1972) are shown for comparison.

atmospheric pressure were carried out in the presence of free surfaces (liquid/vapor interface) (Presnall et al., 1972). The low free energy associated with free surfaces has considerable effects on the extent of supercooling and especially superheating. All these factors and the fact that pressures in the present runs were very much higher have to be borne in mind when comparing the present and previous conductivity curves. At present only the temperatures corresponding to conspicuous discontinuities in conductivity have been used and interpreted as indications of melting and solidification. Any detailed interpretation of the nature of the conductivity variations through melting of basalts has to await the completion of more experiments.

Except for occasional blowouts of the liquid sample. residues of completely or partially molten samples were recovered after cooling and pressure release in a state of recrystallization. There is a noticeable change in color (from dark gray to white or colorless), texture, and transparency. Laue back reflection photographs show that the samples are predominately crystalline. As can be seen from Figure 4 the conductivity values after melting or even partial melting are found to be consistently higher than before melting in agreement with previous investigations. In the case of bulk samples of basalt, this could be attributed partly to an increased homogeneity of the sample and partly to the release of heat during slow progressive solidification on cooling.
On heating through the melting point, on the other hand, the conductivity would appear to be momentarily decreased as a result of structural disorder and due to extraction of the latent heat of fusion.

Abrupt decreases in conductivity for 332B-37-3 suggest onsets of melting just above $1700^{\circ} \mathrm{C}$ at $40 \mathrm{Kbar}$ and just above $1815^{\circ} \mathrm{C}$ at $50 \mathrm{Kbar}$. Onsets of solidification are indicated by conspicuous increases at $1460^{\circ} \mathrm{C}$ at $40 \mathrm{~K}$ bar and near $1500^{\circ} \mathrm{C}$ at $50 \mathrm{~K}$ bar. The decrease in $\sigma$ for $332 \mathrm{~A}-16-1$ at $50 \mathrm{Kbar}$ (Figure 4) puts the melting point for this sample at about $1750^{\circ} \mathrm{C}$. In general, the conductivity is seen to remain at a high value on cooling. The region of $\sigma$ values appears to extend to about $950^{\circ} \mathrm{C}$ at $50 \mathrm{Kbar}$ and down to $1040^{\circ} \mathrm{C}$ at 40 Kbar. The curves at $34,30,25$, and $19 \mathrm{Kbar}$ with activation energies ranging from 0.1 to 0.6 e.v. were determined from runs made after subjection of the sample to partial melting. The results would indicate a gradual recovery of the normal conductivity behavior with release of pressure and/or annealing time after solidification.

\section{ELECTRICAL CONDUCTIVITY VARIATIONS WITH AMBIENT VAPOR PRESSURE OF WATER AND WITH TEMPERATURE}

D.C. electrical conductivity values were determined from resistance measurements on samples contained in a quartz chamber attached to a B.E.T. type highvacuum system. To achieve firm electrical contact between electrodes and samples without undue increase in surface area of material other than the sample under investigation in the test vessel, the actual sample disc, held between Pt electrodes was placed in the center of a stack of five to seven discs, all of the same batch; the complete stack was then wedged into a quartz holder. The electrodes covered about $1 / 3$ of the disc area. All connections were made with $0.05-\mathrm{cm} \mathrm{Pt}$ wire. Measurements were made with the Pt guard ring being connected to ground potential and, most of the time, with an applied voltage of $100 \mathrm{v}$. The maximum percentage error for the determination of $\sigma\left(\mathrm{p} / \mathrm{p}_{\mathrm{o}}\right)$ and $\sigma(\mathrm{T})$, involving resistance measurements, differential pressure, and temperature measurements, was estimated to be less than $\pm 5 \%$.

Pressure readings were taken from a differential manometer by means of a cathetometer (reading accuracy $50 \mu \mathrm{m})$.

The following procedures were adhered to throughout all the tests: (a) outgassing of sample at constant temperature between $15^{\circ}$ and $16^{\circ} \mathrm{C}$ for several hours to a vacuum value of $10^{-6}-10^{-7}$ torr, (b) adsorption and desorption at constant $\mathrm{T}$ between $15^{\circ}$ and $16^{\circ} \mathrm{C}$, followed by exposure to high vacuum, (c) heating of sample in closed system with accumulation of evolving gases, heating in four stages with intermittent removal of gases and cooling to room temperature, (d) heating in high vacuum to about $500^{\circ} \mathrm{C}$, (e) $\mathrm{H}_{2} \mathrm{O}$ adsorption and desorption at constant $\mathrm{T}$ between $15^{\circ}$ and $16^{\circ} \mathrm{C}$ after heating.

The vapor pressure was incremented or decremented in small steps. Both instantaneous and equilibrium 
values of $\sigma$ and $\mathrm{P}$ were recorded. Equilibrium times were of the order of several hours to 1 day.

The values of $\sigma$ of samples as received and prepared in the laboratory atmosphere together with the values obtained after several hours of exposure to high vacuum of $10^{-6}-10^{-7}$ torr at $15-16^{\circ} \mathrm{C}$ are as follows: fusion pump. Immediately noticeable is the hysteresis between heating and cooling curves which increases as the terminal temperature in the heating cycle increases. Moreover, it appears that each heating curve consists of a low temperature region with lower than average activation energy, separated by an inflection from a

\begin{tabular}{llll}
\hline & \multicolumn{2}{c}{$\begin{array}{c}\sigma \\
\text { As Received } \\
\text { and Prepared }\end{array}$} & $\begin{array}{c}\sigma \\
\text { After Initial } \\
\text { Vacuum Exposure }\end{array}$ \\
\cline { 2 - 4 } & \multicolumn{1}{c}{ Initial } & \multicolumn{1}{c}{$\begin{array}{c}\text { Settled } \\
\text { Values }\end{array}$} \\
\hline $332 \mathrm{~A}-16-1,33-36 \mathrm{~cm} \mathrm{(3)}$ & $1.33 \times 10^{-9}$ & $8.25 \times 10^{-10}$ & $1.57 \times 10^{-14}$ \\
$332 \mathrm{~B}-21-1,99-102 \mathrm{~cm}$ & $1.22 \times 10^{-11}$ & $7.3 \times 10^{-11}$ & $8.7 \times 10^{-13}$ \\
$332 \mathrm{~B}-27-2,93-95 \mathrm{~cm}$ & $9.4 \times 10^{-8}$ & $3.3 \times 10^{-9}$ & $7.8 \times 10^{-13}$ \\
$332 \mathrm{~B}-37-2,54-56 \mathrm{~cm}$ & $2.67 \times 10^{-10}$ & $1.88 \times 10^{-10}$ & $1.1 \times 10^{-13}$ \\
\hline
\end{tabular}

Isothermal variations of $\sigma$ with $\mathrm{H}_{2} \mathrm{O}$ adsorption and desorption before heating are shown in Figures 6, 7, and 8 . The values plotted here are equilibrium values, obtained after up to $24 \mathrm{hr}$ of settling time allowed for each step under isothermal conditions. They are substantiated by continuous curves of readings of resistance and residual vapor pressure tending towards the final equilibrium values of both $\sigma$ and $\mathrm{P} / \mathrm{P}_{\mathrm{o}}$. Variations of $\sigma$ with $\mathrm{H}_{2} \mathrm{O}$ vapor pressure from zero to saturation vapor pressure amount to 5.3 to 8 orders of magnitude. The conductivity curves have the broadly S-shaped characteristics of adsorption and desorption isotherms. However, each sample curve has distinct features indicated by different slopes, the several inflections, and the particular shape of hysteresis between adsorption and desorption curves. According to the analysis of irreversible adsorption which has been in good practice with physical chemists, these particular and sometimes peculiar features are significant of distribution, volume, and characteristic shapes of pore and capillary spaces within the sample. The minimum relative changes in $\sigma$ occur in the initial stage of (chemical) adsorption with stronger bonding and in the final stage near saturation in the case of capillary condensation.

Mean isothermal variations of $\sigma$ for three pressure intervals, expressed in values of $\left(\mathrm{P}^{\circ}{ }_{\mathrm{H} 2 \mathrm{O}} / \sigma\right)$ $\left(\Delta \sigma / \Delta \mathrm{P}_{\mathrm{H}_{2} \mathrm{O}}\right)$ provide a suitable basis for a quantitative comparison between the distinct features in the conductivity behavior of different samples. For example:

\begin{tabular}{|c|c|c|c|c|}
\hline & \multicolumn{2}{|c|}{$\begin{array}{c}332 \mathrm{~A}-16-1, \\
33-36 \mathrm{~cm}(3)\end{array}$} & \multicolumn{2}{|c|}{$\begin{array}{c}332 \mathrm{~B}-37-3, \\
54-56 \mathrm{~cm}\end{array}$} \\
\hline & ads. & des. & ads. & des. \\
\hline $0 \leqslant \mathrm{p} / \mathrm{p}_{\mathrm{o}} \leqslant 0.2$ & $1.32 \times 10^{6}$ & -5.2 & 69 & -8.2 \\
\hline $0.4 \leqslant p / p_{0} \leqslant 0.6$ & 20 & -3.7 & 32 & -4.8 \\
\hline $0.8 \leqslant p / p_{0} \leqslant 1.0$ & 0.81 & -0.16 & $1.8 \times 10^{3}$ & -4.6 \\
\hline
\end{tabular}

Variations of $\sigma$ with temperature in a closed system with accumulation of evolved gases is shown in one example for 332B-37-3, 54-56 (Figure 9). Plotted here are the instantaneous values of $\sigma$ for both heating in the closed system and cooling in the system open to the dif- higher temperature region with higher than average activation energy. In each case the steepest section of the latter region coincides with the temperature interval over which significant gas evolution occurs. The cooling curves, on the other hand, appear to follow a common slope which comes close to that determined by the high-vacuum equilibrium values. The excess activation energy, i.e., the difference between the apparent activation energy for the conduction process in the presence of desorbing gases and vapors, and the activation energy for that in high vacuum is, therefore, an indirect measure of the energy (heat) of desorption.

In Figure 9 equilibrium values of $\sigma$ with temperature for heating in vacuum are shown together with the terminal values for $\sigma$ for heating in the closed system. The activation energies in the presence of gases and vapors are lower than those for the samples in the state of completed desorption, except for the regions of active desorption of gases and vapors, presumably mainly $\mathrm{H}_{2} \mathrm{O}$.

\begin{tabular}{|c|c|c|c|c|}
\hline & \multicolumn{2}{|c|}{ High vacuum } & \multicolumn{2}{|c|}{$\begin{array}{c}\text { With Gases } \\
\text { and vapors } \\
\left(\mathrm{H}_{2} \mathrm{O}\right) \text { Desorbing }\end{array}$} \\
\hline & $\begin{array}{c}\epsilon \\
{[\text { e.v. }]}\end{array}$ & $\begin{array}{c}\mathrm{T} \\
{[\mathrm{K}]}\end{array}$ & $\begin{array}{c}\epsilon \\
{[\text { e.v. }]}\end{array}$ & $\begin{array}{c}\mathrm{T} \\
{[\mathrm{K}]}\end{array}$ \\
\hline $332 \mathrm{~A}-16-1$ & $\begin{array}{l}0.67 \\
0.84 \\
0.99\end{array}$ & $\begin{array}{l}518 \\
580 \\
668\end{array}$ & $\begin{array}{l}0.54 \\
0.76 \\
0.86\end{array}$ & $\begin{array}{l}484 \\
580 \\
724\end{array}$ \\
\hline $332 \mathrm{~B}-37-3$ & $\begin{array}{l}0.66 \\
0.64 \\
0.60\end{array}$ & $\begin{array}{l}479 \\
597 \\
677\end{array}$ & $\begin{array}{l}0.42 \\
0.42 \\
1.65\end{array}$ & $\begin{array}{l}480 \\
594 \\
640\end{array}$ \\
\hline $332 \mathrm{~B}-27-3$ & $\begin{array}{l}0.83 \\
0.52 \\
0.76\end{array}$ & $\begin{array}{l}366 \\
572 \\
723\end{array}$ & $\begin{array}{l}0.44 \\
1.42 \\
0.74\end{array}$ & $\begin{array}{l}483 \\
577 \\
712\end{array}$ \\
\hline
\end{tabular}

The maximum difference of $\sim 1$ e.v. gives an estimate of $25 \mathrm{Kcal} \mathrm{mole}^{-1}$ for the heat of desorption.

Results for variations of $\sigma$ with $\mathrm{H}_{2} \mathrm{O}$ adsorption and desorption following several heating cycles and prolonged heating in vacuum, are shown in Figures 10, 11, 


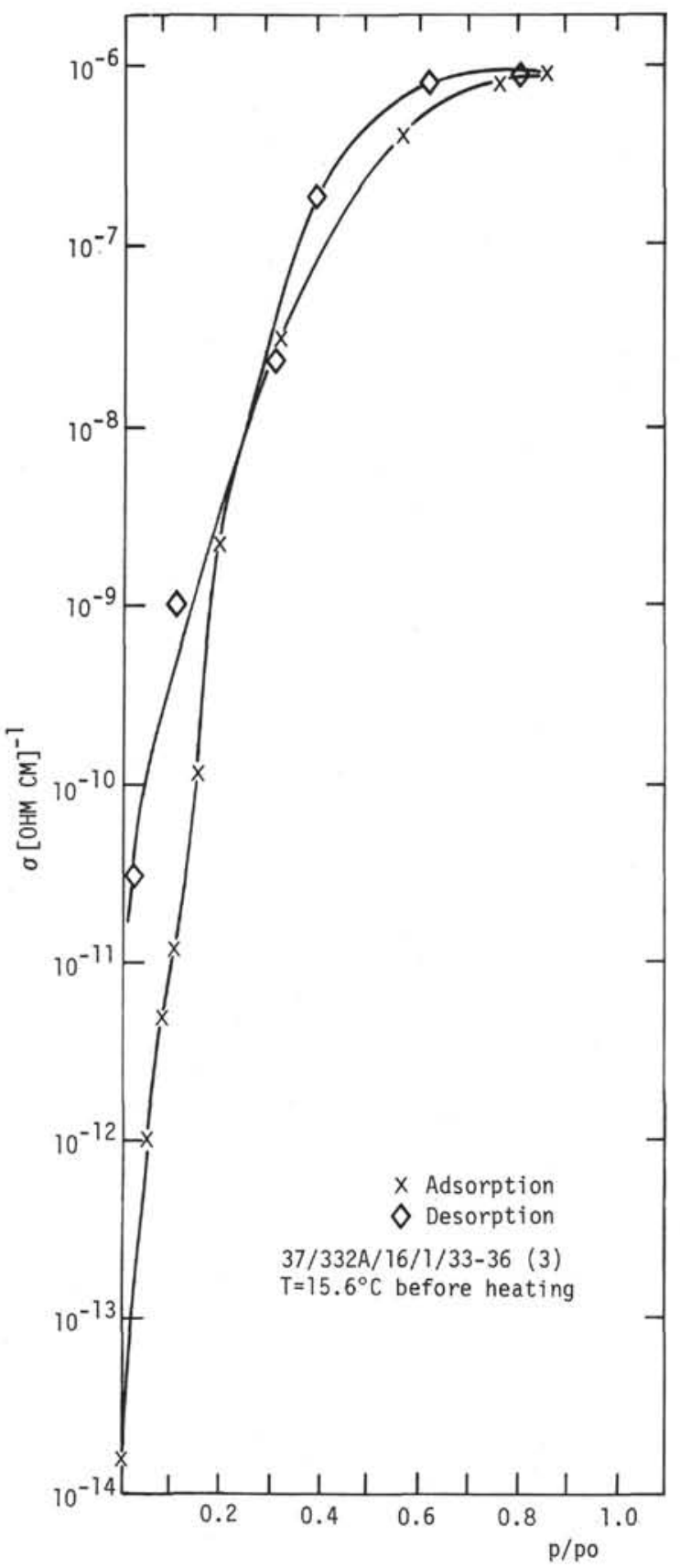

Figure 6. Electrical (dc) conductivity isotherms, for $\mathrm{H}_{2} \mathrm{O}$ adsorption and desorption, as a function of relative vapor pressure before heating.

12. In all cases heating reduces the overall effect of $\mathrm{H}_{2} \mathrm{O}$ adsorption. Moreover, the characteristics of the conductivity isotherms, i.e., slopes as well as the size and nature of the hysteresis, are significantly altered. This is

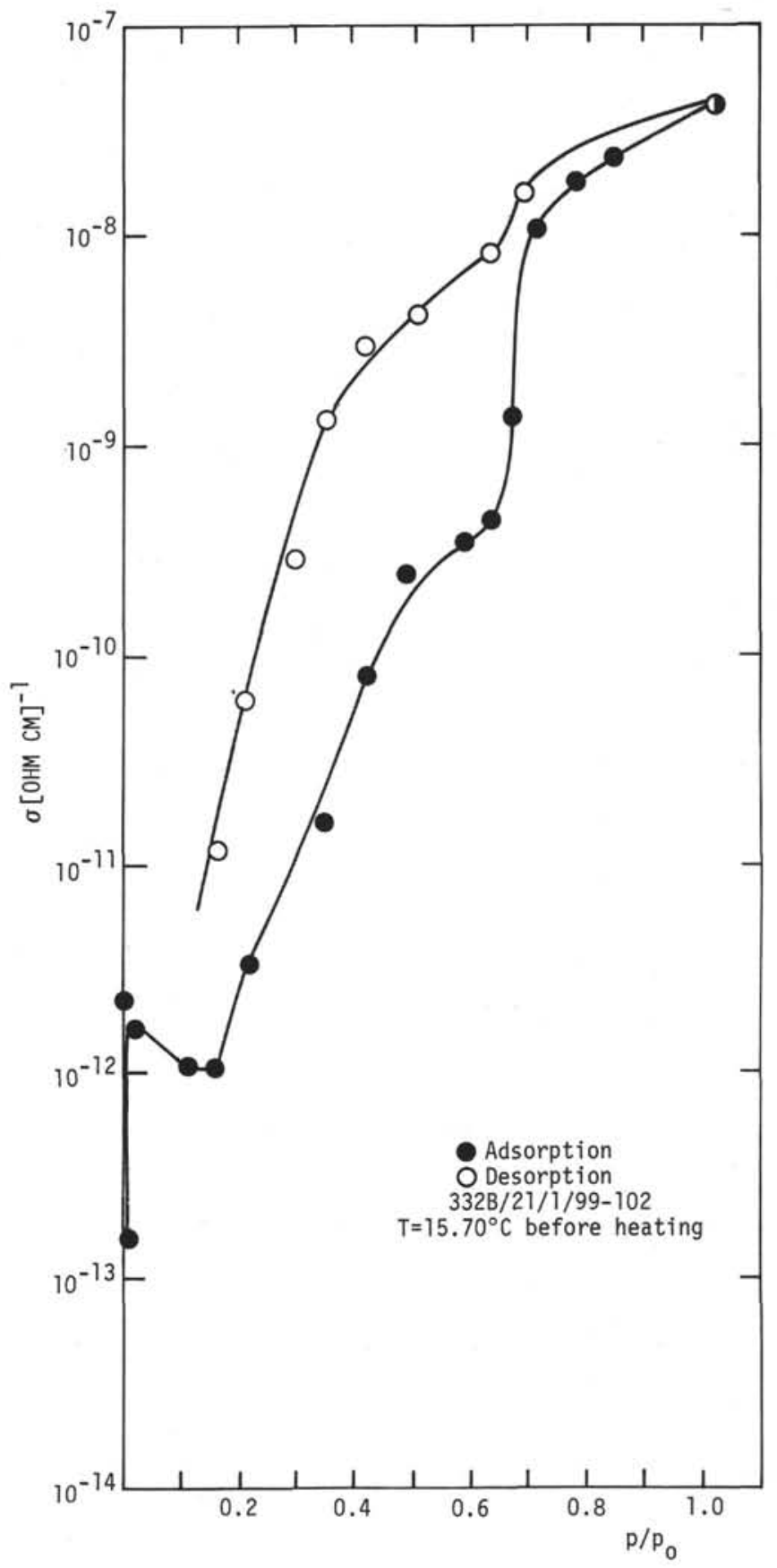

Figure 7. Electrical (dc) conductivity isotherms, for $\mathrm{H}_{2} \mathrm{O}$ adsorption and desorption, as a function of relative vapor pressure before heating.

demonstrated more clearly by considering, as before, the mean isothermal variations $\left(\mathrm{p}^{\circ}{ }_{\mathrm{H} \times} / \sigma\right)$ $\left(\triangle \sigma / \Delta \mathrm{p}_{2} \mathrm{O}\right)$ for three pressure intervals:

\begin{tabular}{|c|c|c|c|c|c|c|}
\hline & \multicolumn{2}{|c|}{$332 \mathrm{~A}-16-1$} & \multicolumn{2}{|c|}{$332 \mathrm{~A}-27-2$} & \multicolumn{2}{|c|}{$332 \mathrm{~B}-37-3$} \\
\hline & ads. & des. & ads. & des. & ads. & des. \\
\hline $9 \leqslant p / p_{0} \leqslant 0.2$ & 74 & -5.5 & $2.6 \times 10^{2}$ & - & $4.6 \times 10^{2}$ & - \\
\hline $0.4 \leqslant p / p_{0} \leqslant 0.6$ & 31 & -4.7 & 8.9 & -4.2 & 42 & - \\
\hline $0.8 \leqslant \mathrm{p} / \mathrm{p}_{\mathrm{o}} \leqslant 1$ & $2.7 \times 10^{2}$ & -3.4 & 24.5 & -3.2 & 75 & - \\
\hline
\end{tabular}


By comparing the curves of $\sigma$ variations with both T and $\mathrm{p} / \mathrm{p}_{\mathrm{o}}$, it is easily seen that a change in $\mathrm{T}$ by $\sim 400^{\circ} \mathrm{C}$ and a change in adsorption from zero to saturation at $\sim 16^{\circ} \mathrm{C}$ produce the same range of change in $\sigma$. However, close to zero vapor pressure, and sometimes close to saturation, the conductivity is many times more sensitive to change of relative vapor pressure than to temperature.

In order to compare the overall effects of temperature and $\mathrm{H}_{2} \mathrm{O}$ adsorption before and after heating, the ratios of the final and initial conductivity $\sigma_{\mathrm{f}} / \sigma_{\mathrm{i}}$ in each run may serve as an indicator:

from the instantaneous changes in $\sigma$ on removal of the accumulated gas pressure at the terminal temperatures. The following are the results in values of $\left(\mathrm{M}_{\mathrm{H}_{2} \mathrm{O}} / \sigma\right)\left(\Delta \sigma / \Delta \mathrm{m}_{\mathrm{H}_{2} \mathrm{O}}\right)$.

\begin{tabular}{cccc}
\hline \multicolumn{2}{c}{$332 \mathrm{~A}-16-1$} & \multicolumn{2}{c}{$332 \mathrm{~B}-37-3$} \\
{$[\mathrm{~K}]$} & {$\left[\mathrm{mole}^{-1}\right]$} & {$[\mathrm{K}]$} & {$\left[\mathrm{mole}^{-1}\right]$} \\
\hline 427 & $1.44 \times 10^{3}$ & 418 & $4.1 \times 10^{2}$ \\
511 & $1.81 \times 10^{2}$ & 505 & $5.5 \times 10^{2}$ \\
607 & - & 619 & $5.8 \times 10^{2}$ \\
751 & 34 & 737 & $5.6 \times 10^{2}$ \\
\hline
\end{tabular}

\begin{tabular}{lcccccc}
\hline & \multicolumn{2}{c}{$332 \mathrm{~A}-16-1$} & \multicolumn{2}{c}{$332 \mathrm{~B}-21-2$} & \multicolumn{2}{c}{$332 \mathrm{~B}-37-3$} \\
\cline { 2 - 7 } & $\sigma_{f} / \sigma_{i}$ & $T_{f}$ & $\sigma_{f} / \sigma_{i}$ & $T_{f}$ & $\sigma_{f} / \sigma_{i}$ & $T_{f}$ \\
\hline $\begin{array}{l}\text { Heating in vacuum } \\
\mathrm{H}_{2} \mathrm{O} \text { adsorption } \\
\text { before heating }\end{array}$ & $5.0 \times 10^{7}$ & $454^{\circ} \mathrm{C}$ & $6.2 \times 10^{7}$ & $450^{\circ} \mathrm{C}$ & $9.1 \times 10^{5}$ & $404^{\circ} \mathrm{C}$ \\
$\begin{array}{l}\mathrm{H}_{2} \mathrm{O} \text { adsorption } \\
\text { after heating }\end{array}$ & $2.8 \times 10^{7}$ & & $5.7 \times 10^{3}$ & & $1.1 \times 10^{7}$ & \\
\hline
\end{tabular}

\section{EVOLUTION OF GASES AND VAPORS WITH TEMPERATURE}

The evolution of gases and vapors, without identification, with heating through four temperature intervals was determined from differential manometer readings. The results for two of the samples, also shown in Figure 13, are given in millimoles and, assuming the evolved gas to be $\mathrm{H}_{2} \mathrm{O}$, in wt \% of sample weight.

\begin{tabular}{|c|c|c|c|c|}
\hline \multirow[t]{2}{*}{$\mathrm{T}[\mathrm{K}]$} & \multicolumn{2}{|c|}{ [millimoles] } & \multicolumn{2}{|c|}{ wt $\%$} \\
\hline & diff. & cum. & diff. & cum. \\
\hline \multicolumn{5}{|c|}{$332 \mathrm{~A}-16-1$} \\
\hline 427 & 0.45 & 0.45 & $3.1 \times 10^{-2}$ & $3.1 \times 10^{-2}$ \\
\hline 511 & 0.38 & 0.83 & $2.7 \times 10^{-2}$ & $5.8 \times 10^{-2}$ \\
\hline 607 & 0.20 & 1.03 & $1.4 \times 10^{-2}$ & $7.2 \times 10^{-2}$ \\
\hline 751 & 0.18 & 0.21 & $1.2 \times 10^{-2}$ & $8.4 \times 10^{-2}$ \\
\hline \multicolumn{5}{|c|}{$332 B-37-3$} \\
\hline 418 & 0.43 & 0.43 & $2.9 \times 10^{-2}$ & $2.9 \times 10^{-2}$ \\
\hline 505 & 0.31 & 0.74 & $2.1 \times 10^{-2}$ & $5.0 \times 10^{-2}$ \\
\hline 619 & 0.29 & 1.03 & $2.0 \times 10^{-2}$ & $7.0 \times 10^{-2}$ \\
\hline 737 & 0.20 & 0.23 & $1.4 \times 10^{-2}$ & $8.4 \times 10^{-2}$ \\
\hline
\end{tabular}

The temperatures given are the terminal temperatures at which the gas pressure came to equilibrium.

The energies of desorption for the four temperatures for sample 332B-37-3, as determined from ClausiusClapeyron plots, are as follows:

\begin{tabular}{cc}
\hline Temperature Interval & $\mathrm{H}_{\mathrm{A}}\left[\mathrm{Kcal} \mathrm{mole}^{-1}\right]$ \\
\hline $300-418 \mathrm{~K}$ & 13.6 \\
$418-505 \mathrm{~K}$ & 17.9 \\
$505-619 \mathrm{~K}$ & 45.3 \\
$619-737 \mathrm{~K}$ & 88.6 \\
\hline
\end{tabular}

The sensitivity of $\sigma$ to water vapor adsorption and desorption at elevated temperatures can be inferred
The contrast between rapidly diminishing and rather constant effectiveness of the desorbing species with temperature, as observed for the two samples, does not appear to be related to the heat of desorption and thus to strength of bonding but rather to the specific nature of the desorbing species interacting with the conduction mechanisms.

\section{REFERENCES}

Bradley, R.S., Jamil, A.K., and Munro, D.C., 1964. The electrical conductivity of olivine at high temperatures and pressures: Geochim. Cosmochim. Acta, v. 28, p. 16691678.

Bradley, R.S., Clark, J.P., Munro, D.C., and Singh, D., 1970. Studies by electrical conductivity methods at elevated pressures and temperatures of ultramarine and related minerals: Geochim. Cosmochim. Acta, v. 36, p. 471-480.

Bridgman, P.W., 1931. The Physics of High Pressure: New York (Dover Inc.), p. 322.

Carslaw, H.S. and Jaeger, J.C., 1959. Conduction of heat in solids, 2nd ed., Oxford (Clarendon Press), p. 188-193.

Coster, H.P., 1948. The electrical conductivity of rocks at high temperatures: Geophys. J. Roy. Astron. Soc., v. 5, p. 193-199.

Darbha, D.M. and Schloessin, H.H., 1975. Anisotropic lattice thermal conductivity of $\alpha$-quartz as a function of pressure and temperature. In 11 th Internat. Conf. Thermal Conductivity Proc.: New York (Plenum Press).

Dvorak, Z. and Schloessin, H.H., 1973. On the anisotropic electrical conductivity of enstatite as a function of pressure and temperature: Geophysics, v. 38, p. 25-36.

Gonvec, H., 1962. Etude cinétique de l'échange du sodium de constitution bleu d'outremer avec l'ion argent en solution alcoolique ou acétonique: Compt. Rend., v. 254, p. 3659 61.

Hughes, H.J., 1955. The pressure effect on the electrical conductivity of peridot: J. Geophys. Res., v. 60, p. 187-191.

Hyndman, R.O. and Jessop, A.M., 1972. The Mid-Atlantic Ridge near $45^{\circ} \mathrm{N} X V$. Thermal conductivity of dredge and drill core samples; Canadian J. Earth Sci., v. 8, p. 391393. 


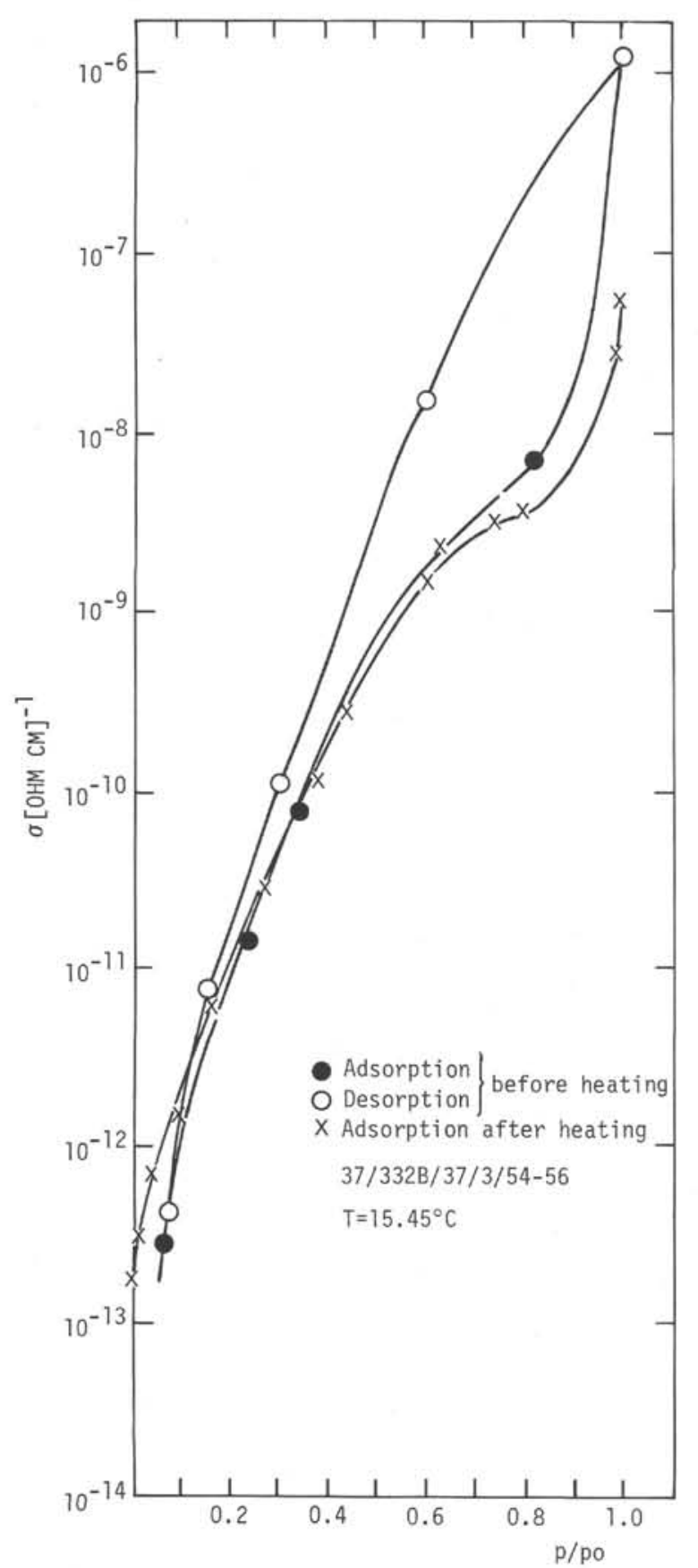

Figure 8. Electrical (dc) conductivity isotherms, for $\mathrm{H}_{2} \mathrm{O}$ adsorption and desorption, as a function of relative vapor pressure before heating.

Jost, W. and Mennenöh, S., 1950. Z. Phys. Chem., v. 196, p. 188.

Khitarov, N.I., Slutskiy, A.B., and Pugin, V.A., 1970. Electrical conductivity of Basalts at high $\mathrm{T}$ and $\mathrm{P}$ and phase transitions under upper mantle conditions: Phys. Earth Planet. Interiors, v. 8, p. 334-342.

Kushiro, I., Syono, Y., and Akimoto, S., 1968. Melting of a perioditite nodule at high pressures and high water pressures: J. Geophys. Res., v. 73, p. 6023-6029.

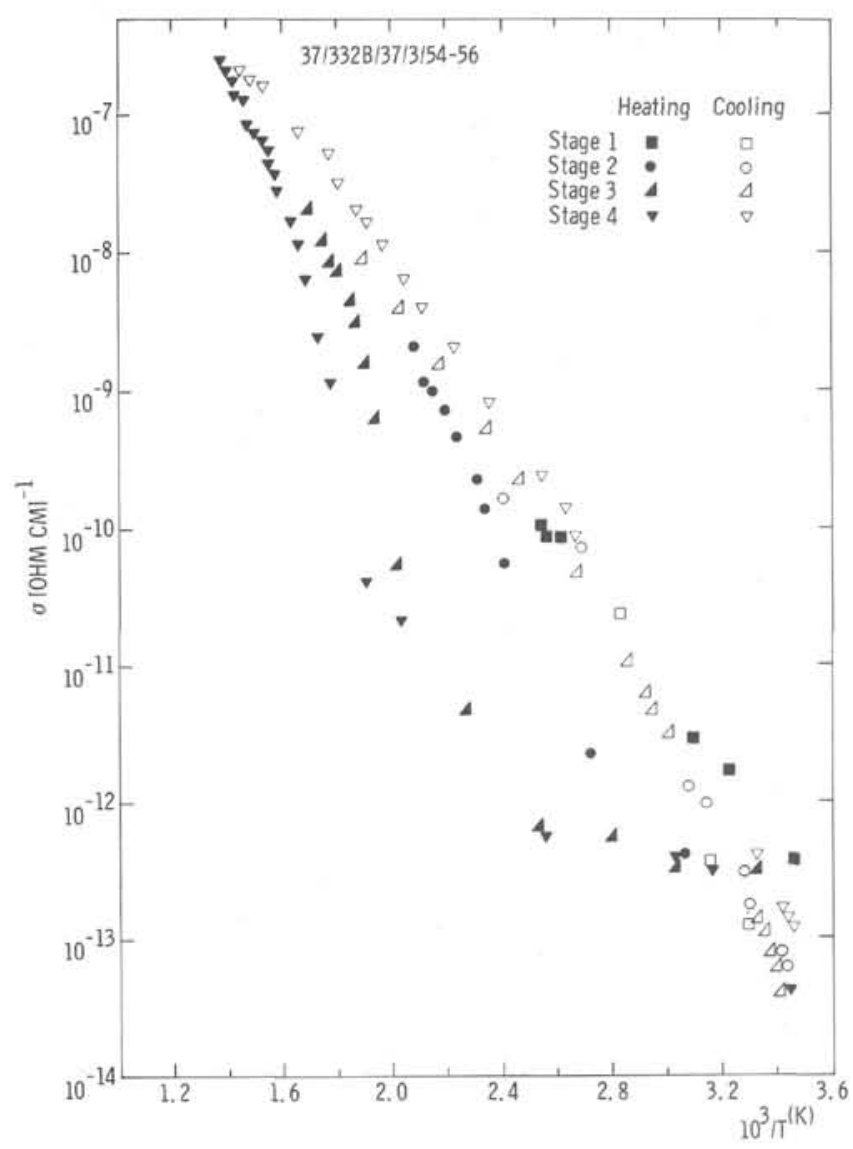

Figure 9. Variations of $\sigma$ versus $1 / T$ showing instantaneous values during heating with accumulation of evolved gases in a closed system and during cooling in an open system.

Lebedev, E.B. and Khitarov, N.I., 1964. Dependence of the beginning of melting of granite and the electrical conductivity of its melt on high vapor pressure: Geochem. Int., v. 1, p. 193-197.

Petrunin, G.I., Yurchak, R.I., and Tkach, G.F., 1971. Temperature conductivity of Basalts at temperatures from 300 to $1200^{\circ} \mathrm{K}$, Izv: Earth Phys., v. 2, p. 65-68.

Poole, H.H., 1914. On the thermal conductivity and specific heat of granite and basalt at higher temperatures: Phil Mag., v. 27 , p. $58-83$.

Presnall, D.C., Simmons, C.L., and Porath, H., 1972. Changes in electrical conductivity of a synthetic basalt during melting: J. Geophys. Res., v. 77, p. 5665-5672.

Scheidegger, K.F., 1973. Temperatures and compositions of magmas ascending along Mid-Ocean ridges: J. Geophys. Res., v. 78, p. 3340-3355.

Schloessin, H.H. and Dvorak, Z., 1972. Anisotropic lattice thermal conductivity in Enstatite as a function of pressure and temperature: Geophys. J. Roy. Astron. Soc., v. 27, p. $499-516$.

Walsh, J.B., 1973. Theoretical bounds for thermal expansion, specific heat, and strain energy due to internal stress: J. Geophys. Res., v. 78, p. 7637-7646. 


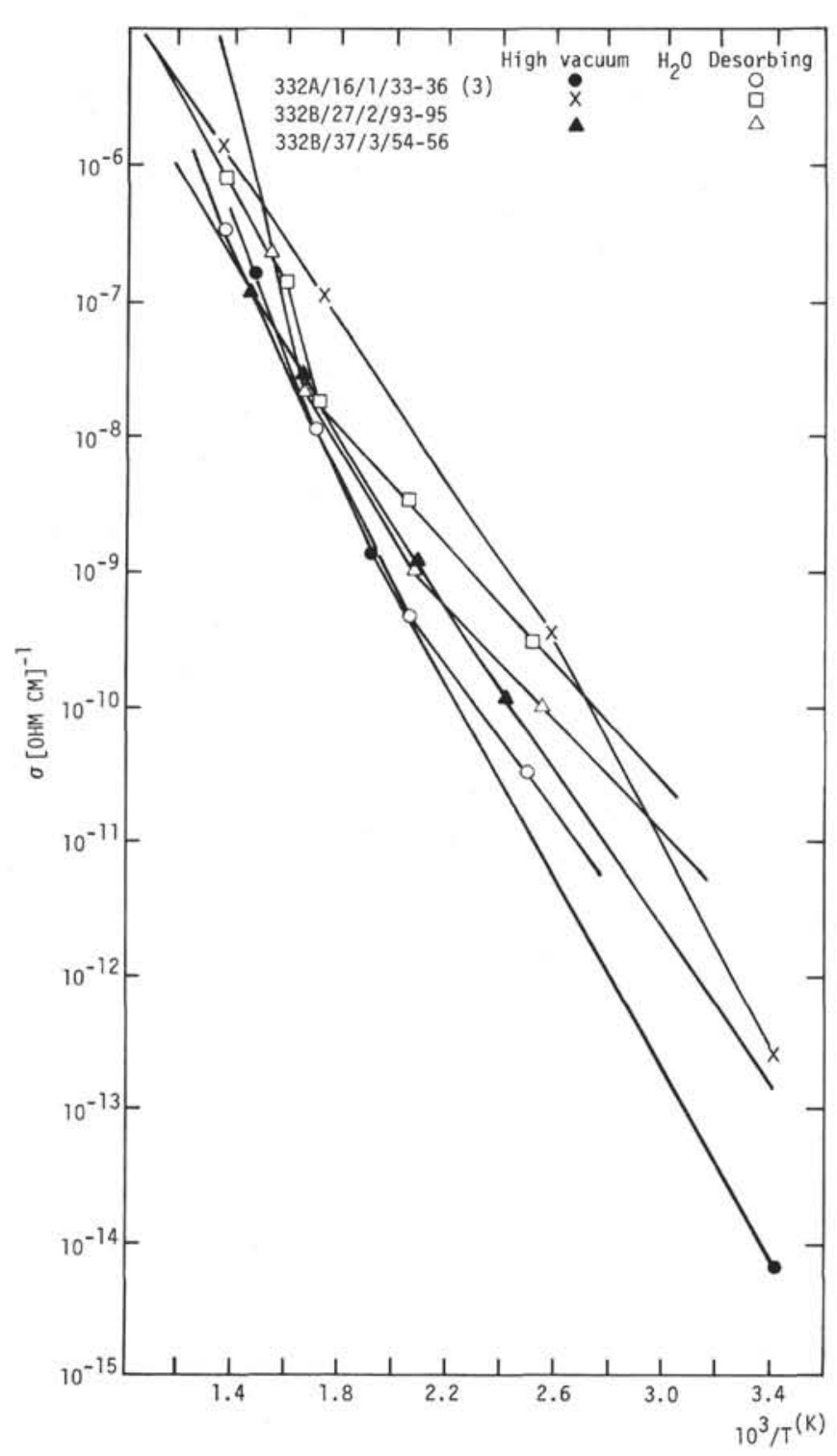

Figure 10. Equilibrium values of $\sigma$ versus $1 / T$ in vaccum and with $\mathrm{H}_{2} \mathrm{O}$ desorbing.

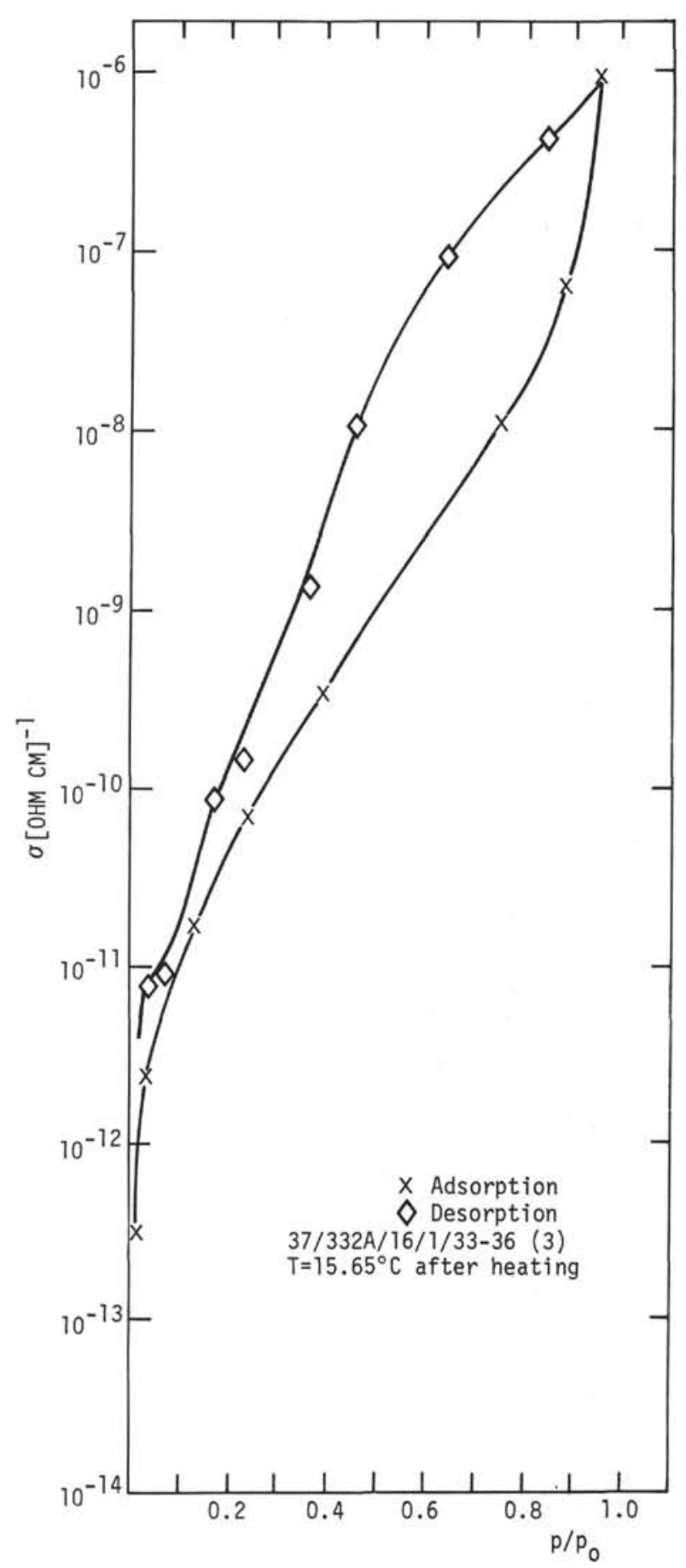

Figure 11. Conductivity isotherms, for $\mathrm{H}_{2} \mathrm{O}$ adsorption, after prolonged heating. 

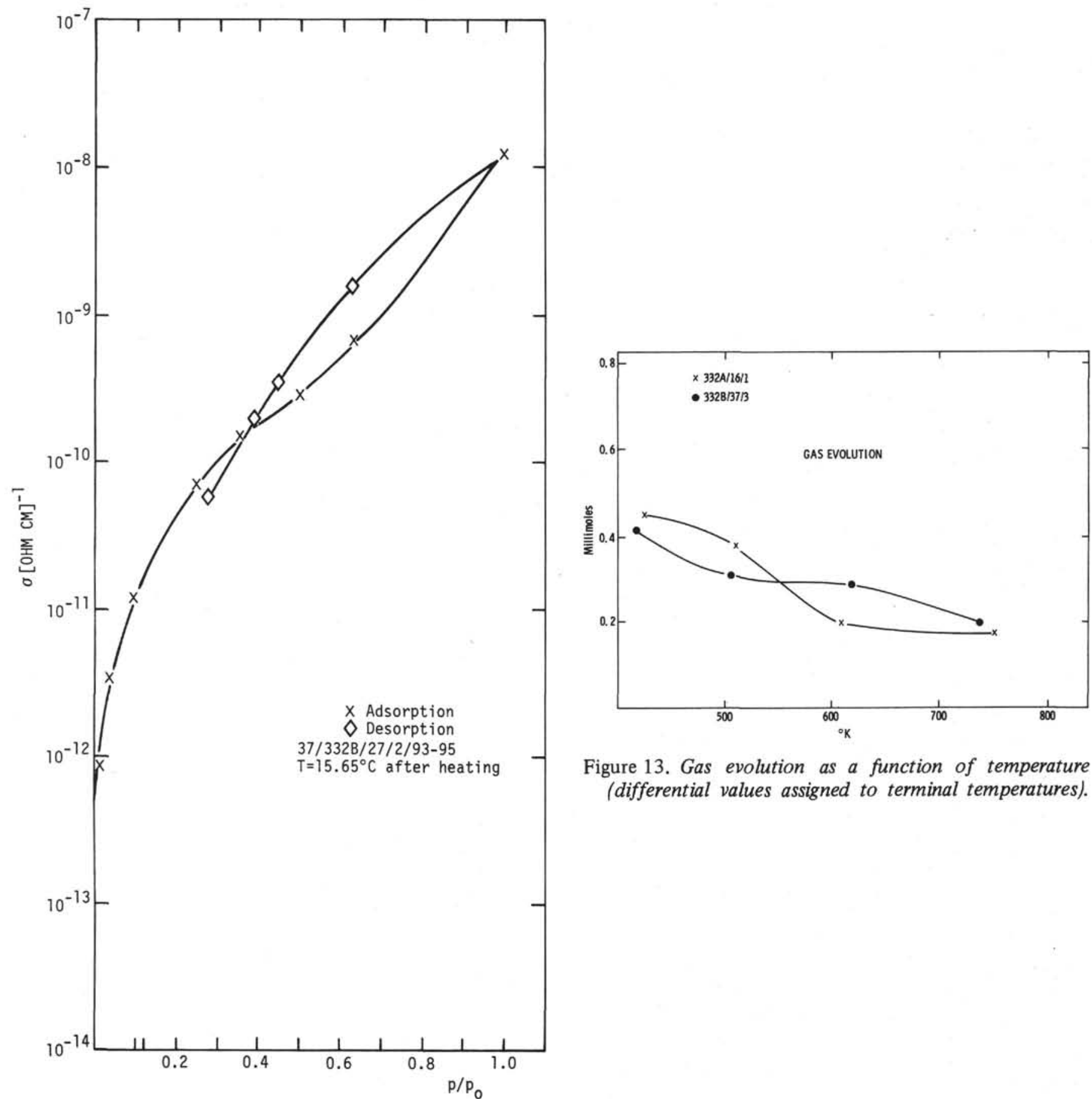

Figure 13. Gas evolution as a function of temperature (differential values assigned to terminal temperatures).

Figure 12. Conductivity isotherms, for $\mathrm{H}_{2} \mathrm{O}$ adsorption, after prolonged heating. 


\section{PLATE 1}

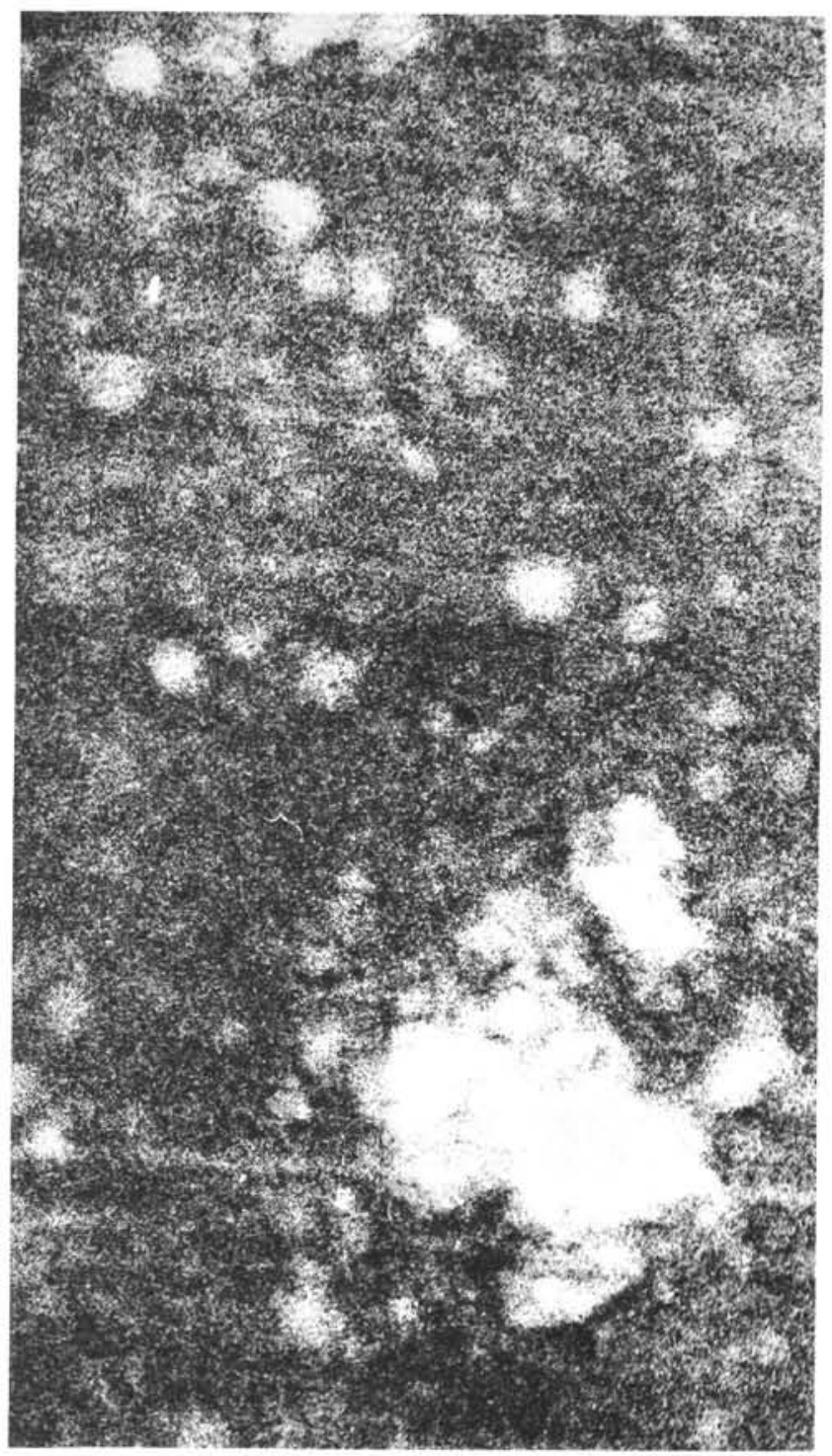

\section{PLATE 2}

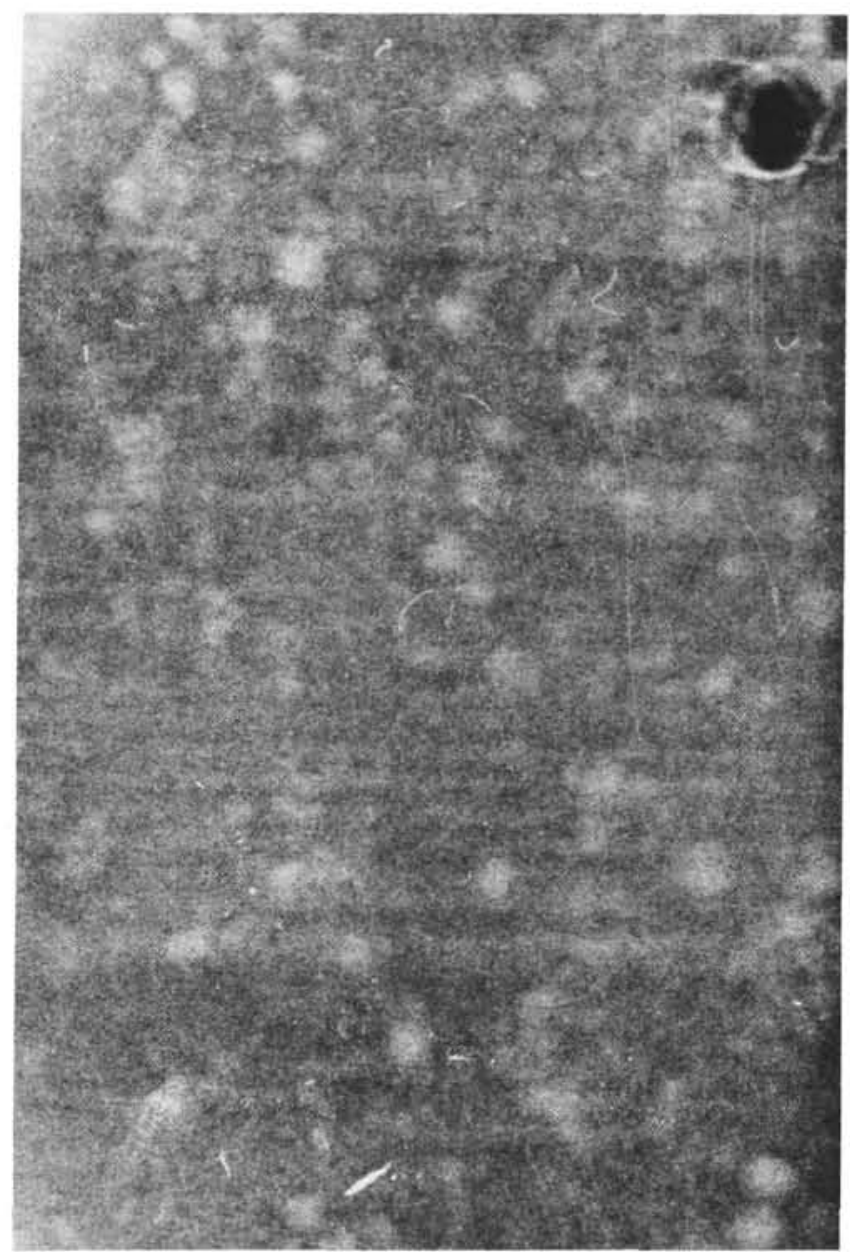

Direct beam X-ray topographs $\left(2 \theta=13^{\circ}, M_{O} K \alpha\right)$ for Samples 332B-27-2, and 332B-37-3. Light areas represent higher densities (striping is an artifact caused by the slit). 
PLATE 4

PLATE 3
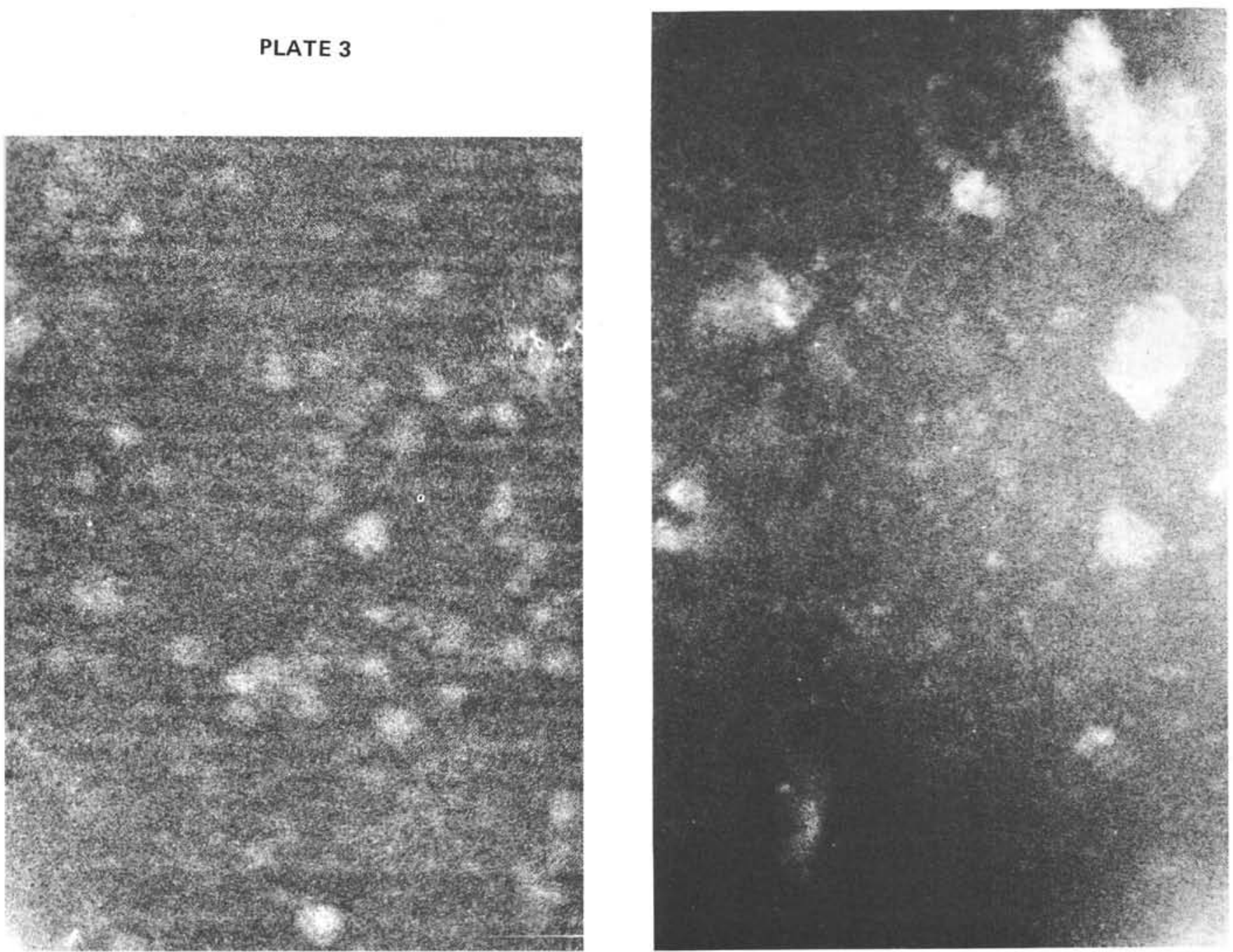

Direct beam X-ray topographs $\left(2 \theta=3^{\circ}, M_{0} K \alpha\right)$ for Samples 332A-16-1, and 332B-21-1. Light areas represent higher densities (striping is an artifact caused by the slit). 